\title{
The Five Factors influencing Software Architecture Modeling and Evaluation Techniques
}

\author{
Hassan Almari \\ Australian National University, \\ CSIT Building 108 North road \\ Canberra, ACT 0200, Australia \\ email: hassan.almari@anu.edu.au
}

\author{
Clive Boughton \\ Australian National University, \\ CSIT Building 108, North road \\ Canberra, ACT 0200 Australia \\ Chairman and Director of Software Improvements \\ GPO Box 1928, Canberra, ACT 2601, Australia \\ email: clive.boughton@anu.edu.au
}

\begin{abstract}
Two of the most important aspects that help architects to describe, automate, and evaluate architecture artefacts with precision include the use of Software Architecture (SA) modeling languages, and the selection of SA evaluation methods. Accurate, verifiable architecture descriptions are more likely to result in successful software development outcomes. There appears to be an unnatural and significant disconnect between $\mathrm{SA}$ artefacts and both preand post-architecture development artefacts. The disconnect seems to exist for various, sometimes unrelated, reasons not all of which have yet been fully investigated. In an effort to confirm (some of) the factors that influence effective utilization of software/system architecture artefacts in the process of software/system development, the author(s) of this paper try to address the aforementioned problem by focusing on the investigation of five factors that influence SA evaluation and its automation process. These factors include: Formality of SA descriptions; modelling of SA; SA documentation; standardisation of $\mathrm{SA}$; and current $\mathrm{SA}$ evaluation tools. Contributing to the identification of these five influential factors, and their discussion, is a section of a questionnaire which was broadly aimed at discussing matters relating to software/system architecture descriptions and evaluation in industry.
\end{abstract}

Index Terms-Automation, Documentation, Evaluation, Languages, Measurement, Software Architecture (SA), Standardization, Utilization Factors.

\section{INTRODUCTION}

$\mathrm{T}$ HERE are many factors that influence the utilization of software/system architecture and its evaluation method in industry today. So a questionnaire was drafted to gather the experiences of software/system developers with software architecture artefacts, and identify the evaluation methods that they use in their work.

Most importantly, the questionnaire's aim was to identify the factors that encourage or hinder the utilization of software architecture by the developers as well as their evaluation methods; and also, to point to some aspects that could improve the automation of SA. This report analyses five particular factors in an effort to arrive at applicable solutions to increase awareness and improve the utilization and automation of software/system architecture artefact in industry.

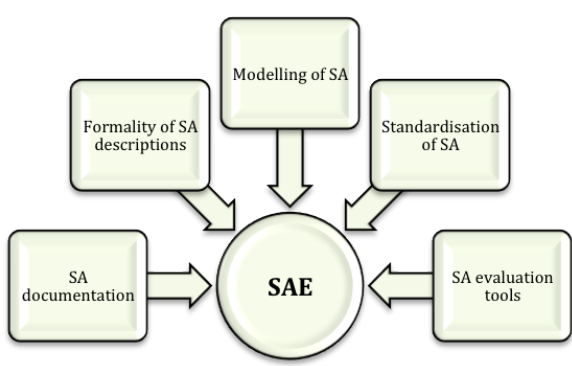

Fig. 1. The five factors influencing Software Architecture Evaluation (SAE)

\section{ANALYSIS PROCEDURE}

The original questionnaire used in this research comprised 23 questions. The questions were grouped into various sections such that each section could focus on a specific objective.

The first section focused on learning more about who responded to the questionnaire in terms of their area of expertise, the sectors in which they have worked, the length of experience and their familiarity with software/system architecture. This was important in regard to analysing their responses to the main questions more accurately. The next section pertains to the first part on which this report focuses: discovering the factors that encourage and discourage the utilization of system/software architecture by developers in their work. Finally, the third section mainly concentrated on the evaluation methods used by developers for system/software architecture artefacts. The main task here was to gather the experience of participants with evaluation methods, hence determine the main factors that could support or hinder the use of SA artefacts and their quantitative evaluation.

Both single dimensional and two dimensional analysis were used to achieve the objective outlined in this report.

Four questions out of 23 in the questionnaire were picked and analysed to draw conclusion about the factors that influence SA artefacts' utilization as well as factors that affect automation of SA quantitative evaluation. These include Q6, Q7, Q13 and Q14. The two former ques- 
tions focused on software/system architecture utilization and automation, while the latter two questions focused on software/system evaluation.

In order to draw more meaningful conclusions, an evaluation of how the various factors and opinions obtained from the responses to each individual question in the questionnaire affect, or relate to each other, was conducted. This meant carrying out a two-dimensional analysis, where selected questions were analysed as pairs in different combinations based on the study objectives. Appropriate analysis methods were used to draw conclusions on the cross- relationship between the various aspects presented by each question.

All of the four questions were multiple choice in which the researchers proposed some of the possible factors and the participants were to choose at most two of the factors according to their experience. The analysis in the single dimension thus involved tabulating the results in a frequency table to determine the percentage of respondents who chose each of the suggested (main) factors. The conclusion was arrived at by comparing all the factors according to the number of respondents who chose them. A majority percentage was translated to be a suggested main factor the choices presented. These results were also illustrated on a bar chart for ease of visualization, where the height of each bar corresponded to the count of respondents who chose the factor under consideration.

In order to determine how other factors presented in all the questions of the questionnaire affected the responses above, a two dimensional analysis was also employed as in Table I, where each matrix is a combination of two questions.

Due to the length of analysis of the four questions (Q6, Q7, Q13 and Q14) which surpasses the page limitation, only the significant results in the analysis were chosen and discussed for all the two dimensional analyses in this report. The main method used to analyse the crossrelationship in this case was cross-tabulation. Other techniques such as the Pearson $\chi^{2}$ test, independent sample ttest and ANOVA were also used to analyse the significance of the relationships.

Normality of the items were tested using Shapiro-Wilk $\mathrm{W}$ test as this test has the best power for a given significance, followed closely by Anderson-Darling when comparing the ShapiroWilk, KolmogorovSmirnov, Lilliefors, and Anderson-Darling test, [1]. The randomness of missing values were tested using Little's MCAR test.

\section{RATIONALE OF THE ANALYSIS METHOD SELECTED}

There were many ways that the data from the questionnaire could have been analysed in order to arrive at some conclusion. However, careful consideration was given to selecting the methods of presenting and analysing the responses to the questionnaire in order to ensure that the conclusions arrived at were accurate and reliable. The following section discusses some of the factors that were considered in choosing the methods to perform the analysis.

\section{A. Individual analysis methods}

For one dimensional analysis, the method chosen to analyse the responses to each question in the questionnaire depended largely on the type of question. All of the four questions analysed for this paper involved multiple choices in which the respondents were allowed to pick any two. It is important to note that there are many factors that could influence the utilization of modelling techniques in system/software architecture description. Similarly, there are many factors that could influence quantitative evaluation for software architectures. Given the diversity of the respondents who participated in the questionnaire, it could therefore be expected that the factors they identified varied widely. If the questions were left open-ended, it would be hard to analyse the responses quantitatively. For this reason, the questionnaire was designed in such a way that the most common factors were identified by the researchers based on past experience and analysis.

The identified measures discussed above enabled quantitative analysis in which the importance of a factor was gauged by the number of respondents who chose it. Thus, it was appropriate to analyse the results using a frequency table for each of the questions. A pie chart was not appropriate for representation of these results pictorially since respondents were allowed to identify more than one factor, therefore the results did not total up to $100 \%$. For this reason, a bar chart was more appropriate.

\section{B. Multi-dimensional analysis methods}

Since the four questions were close-looped, one dimensional analysis alone would not have been sufficient to draw meaningful conclusions. It was necessary to identify the trend in the responses given by the various respondents based on their responses to the rest of the questions. For this purpose, all significant results from all combinations in the two dimensional analysis that included any of the four questions relevant to in this paper were analysed alongside the selected questions in the survey (see Table I), to determine the relationships that could be present, thus contributing to this study's objectives.

For cross-comparison with questions which involved a nominal scale such as Q2-Q8, Q13 and Q14, cross tabulation was considered more appropriate. In order to determine the level of dependency between the two questions under examination in each case, a Pearson-Chi Square test was conducted on each of the pairs too.

Questions 9 and 10 as well as Q15 to Q23 involved an ordinal scale. For this category of questions, it was necessary to use independent sample t-tests to deduce a cross-relationship with the chosen question in two dimensional analysis.

In the two dimensional analysis, most of the questions did not yield any significant results regarding the relationship between them. This led to the conclusion that three 
TABLE I

Two Dimensional Matrices

\begin{tabular}{cccccccccccccccccccccc}
\hline Quest. \# & $\mathrm{Q}_{2}$ & $\mathrm{Q}_{3}$ & $\mathrm{Q}_{4}$ & $\mathrm{Q}_{5}$ & $\mathrm{Q}_{6}$ & $\mathrm{Q}_{7}$ & $\mathrm{Q}_{8}$ & $\mathrm{Q}_{9}$ & $\mathrm{Q}_{10}$ & $\mathrm{Q}_{11}$ & $\mathrm{Q}_{12}$ & $\mathrm{Q}_{13} \mathrm{Q}_{14}$ & $\mathrm{Q}_{15}$ & $\mathrm{Q}_{16}$ & $\mathrm{Q}_{17}$ & $\mathrm{Q}_{18}$ & $\mathrm{Q}_{19}$ & $\mathrm{Q}_{20}$ & $\mathrm{Q}_{21}$ & $\mathrm{Q}_{22}$ & $\mathrm{Q}_{23}$ \\
\hline $\mathrm{Q}_{6}$ & $\mathrm{X}_{1}$ & $\mathrm{X}_{2}$ & $\mathrm{X}_{3}$ & $\mathrm{X}_{4}$ & & $\mathrm{X}_{5}$ & $\mathrm{X}_{6}$ & $\mathrm{X}_{7}$ & $\mathrm{X}_{7}$ & & $\mathrm{X}_{8}$ & $\mathrm{X}_{9}$ & $\mathrm{X}_{10}$ & $\mathrm{X}_{11}$ & $\mathrm{X}_{12}$ & $\mathrm{X}_{13}$ & $\mathrm{X}_{14}$ & $\mathrm{X}_{15}$ & $\mathrm{X}_{16}$ & $\mathrm{X}_{17}$ & $\mathrm{X}_{18}$ \\
\hline $\mathrm{Q}_{7}$ & $\mathrm{X}_{19}$ & $\mathrm{X}_{20}$ & $\mathrm{X}_{21}$ & $\mathrm{X}_{22}$ & $\mathrm{X}_{5}$ & & $\mathrm{X}_{23}$ & $\mathrm{X}_{24}$ & $\mathrm{X}_{24}$ & & $\mathrm{X}_{25} \mathrm{X}_{26}$ & $\mathrm{X}_{27}$ & $\mathrm{X}_{28}$ & $\mathrm{X}_{29}$ & $\mathrm{X}_{30}$ & $\mathrm{X}_{31}$ & $\mathrm{X}_{32}$ & $\mathrm{X}_{33}$ & $\mathrm{X}_{34}$ & $\mathrm{X}_{35}$ \\
\hline $\mathrm{Q}_{13}$ & $\mathrm{X}_{36}$ & $\mathrm{X}_{37}$ & $\mathrm{X}_{38}$ & $\mathrm{X}_{39}$ & $\mathrm{X}_{8}$ & $\mathrm{X}_{25}$ & $\mathrm{X}_{40}$ & $\mathrm{X}_{41}$ & $\mathrm{X}_{42}$ & $\mathrm{X}_{43}$ & $\mathrm{X}_{44}$ & $\mathrm{X}_{45}$ & $\mathrm{X}_{46}$ & $\mathrm{X}_{47}$ & $\mathrm{X}_{48}$ & $\mathrm{X}_{49}$ & $\mathrm{X}_{50}$ & $\mathrm{X}_{51}$ & $\mathrm{X}_{52}$ & $\mathrm{X}_{53}$ & $\mathrm{X}_{54}$ \\
\hline $\mathrm{Q}_{14}$ & $\mathrm{X}_{55}$ & $\mathrm{X}_{56}$ & $\mathrm{X}_{57}$ & $\mathrm{X}_{58}$ & $\mathrm{X}_{9}$ & $\mathrm{X}_{26}$ & $\mathrm{X}_{59}$ & $\mathrm{X}_{60}$ & $\mathrm{X}_{61}$ & $\mathrm{X}_{62}$ & $\mathrm{X}_{63}$ & $\mathrm{X}_{45}$ & $\mathrm{X}_{46}$ & $\mathrm{X}_{47}$ & $\mathrm{X}_{48}$ & $\mathrm{X}_{49}$ & $\mathrm{X}_{50}$ & $\mathrm{X}_{51}$ & $\mathrm{X}_{52}$ & $\mathrm{X}_{53}$ & $\mathrm{X}_{54}$ \\
\hline
\end{tabular}

Where:

- $\mathrm{X}_{\mathrm{i}}$ - is the matrix number;

- empty cell: No combinations been selected.

dimensional or 4-dimensional analyses were all invalid due to low cell expected frequencies.

\section{STUDY FINDINGS}

Taking into consideration all the analysis precautions above, this study yielded the following results regarding the most important factors that influence the use of modelling techniques in the description of system/software architecture, as well as the most important factors that either support or hinder automation for SA.

Before proceeding to analysis, missing value analysis was performed to see whether the pattern of missing values were completely random. None of the main questions Q6, Q7, Q13 and Q14 do not have any missing values. All of the Likert scaled statements (Q9, Q10, Q15 Q23) had less than 15 percent missing values, the percentage of missing values were within the range of $\left(\begin{array}{ll}8 & 12\end{array}\right)$ percent except Q18 and Q23, they had 14 percent missing values. The Little's MCAR test was insignificant, $\left(\chi^{2}=40.72, \mathrm{df}=62\right.$, $\mathrm{p}$-value $=.983>.05)$. So, the missing value patterns were completely random and hence they would not create any biasedness in test results.

\section{A. One dimensional Analyses}

As shown in Figure 2, according to the majority of respondents, the main factor that encourages the utilization of modelling techniques in describing software/system architecture is the fact that it is "easier to demonstrate the software/ system concepts and features" as identified by $60 \%$ of the respondents. A further, $28 \%$ noted that “it makes designers'/programmers' job much easier". The remaining factors were all considered as less important even though participants were able to select two of the available choices.

Four out of 50 respondents did not respond to this question. The possible reason for this could be that the respondents had no experience working with system/software architecture, and so (in all honesty) they could not comment on the factors that influence or hinder their use.

Figure 2, depicts clearly that the use of models indeed makes it easy to demonstrate the software/system concepts and features. This is a major factor that supports the use of models in system/software architecture description.

The respondents also singled out "the difficulty in integrating system/software models with other artefacts such

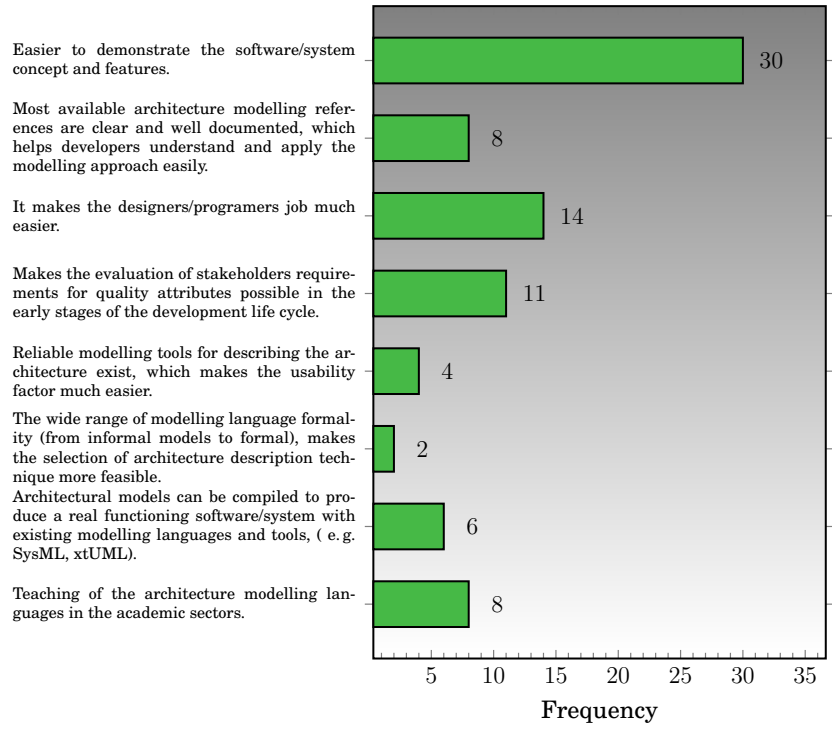

Fig. 2. Encouraging factors for the utilization of models to describe software/system architecture.

as Design Models" as the main factor that discourages the use of modelling techniques in system/software architecture description. Closely following this is "the lack of standardization between the existing architecture modelling techniques, notions and semantics". This SA standardization challange was identified by [2]. Furthermore, 22\% acknowledged in the previous question that the use of models "makes the evaluation of stakeholders requirements

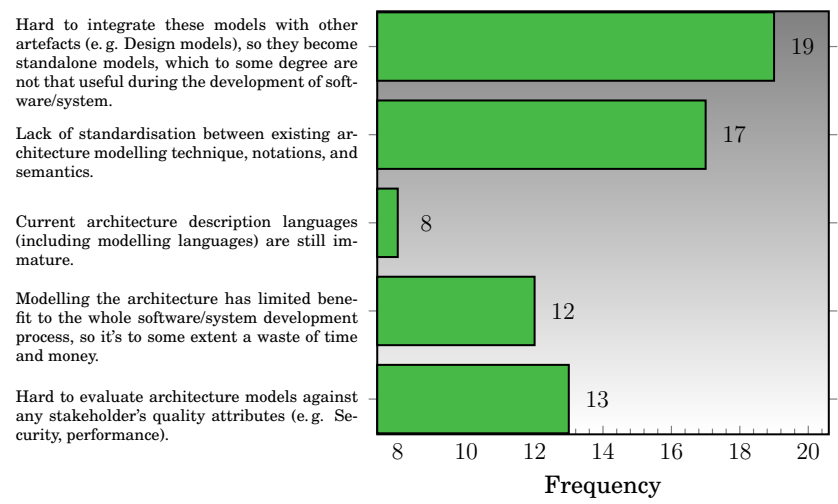

Fig. 3. Discouraging factors for the utilization of models to describe soft- ware/system architecture. 
TABLE II

IMPORTANT FACTORS THAT COULD SUPPORT QUANTITATIVE EVALUATION FOR ANY SA

\begin{tabular}{lccc}
\hline $\begin{array}{l}\text { What are the most important factors that could } \\
\text { SUPPORT quantitative evaluation for any software } \\
\text { architecture (SA)? You may choose two. }\end{array}$ & Responses & $\begin{array}{c}\text { Percentage based on who responds } \\
\text { to this question (N'=43) }\end{array}$ & $\begin{array}{c}\text { Percentage based on total } \\
\text { responses (N=50) }\end{array}$ \\
\hline The language used for describing SA & 7 & $16.3 \%$ & $14.0 \%$ \\
\hline Formality level of SA description & 12 & $27.9 \%$ & $24.0 \%$ \\
\hline $\begin{array}{l}\text { Using standard language and architecture framework } \\
\text { for describing SA }\end{array}$ & 20 & $46.5 \%$ & $40.0 \%$ \\
\hline Tools availability for describing and evaluating SA & 22 & $51.2 \%$ & $44.0 \%$ \\
\hline Documenting mechanism used during SA description & 9 & $20.9 \%$ & $18.0 \%$ \\
\hline
\end{tabular}

for quality attributes possible in the early stages of the development life cycle", $26 \%$ reckon that it is "hard to evaluate architecture models against any stakeholder's quality attributes (e. g. Security, performance)". A further $24 \%$ think that "modelling the architecture has limited benefit to the whole software/system development process, so it's to some extent a waste of time and money". Finally, $16 \%$ of the respondents pointed out that "current architecture description languages (including modelling languages) are still immature".

As can be observed in Figure 3 all the factors identified above carry some weight as hindrances to the use of modelling in software/system architecture description. All the five factors thus need to be taken into careful consideration in efforts to encourage developers to use models in their work. Although, there are a recognised effort done to improve some of the areas that hinder the use of, frameworks and models to describe and document SA, such as [3], [4], [5], [6], and [7]. However, More research and effort need to be made, to improve the utilization and usability factors of SA modeling techniques.

Comparing the responses to the two questions, we believe that the factors that discourage the use of models in SA description far outweigh the factors that may support or encourage their use. This leads us to conclude that even though the use of modelling techniques in system/software architecture description is important, there is still a lot that needs to be done to make the process more effective and easier to use for developers.

As identified above, it is clear that there is a divided view about the contribution of modelling in making the process of evaluation effective. This is because evaluation of software architecture in general, is a fundamental component of development that should be embraced by all developers. While some of the developers have embraced quantitative evaluation for SA, there are still many others who haven't used it. This is influenced by a number of factors.

According to the analysis of responses which are shown as percentage frequency in Table II, the main factor that could support quantitative evaluation for any SA is "the availability of tools for describing and evaluating software architecture". This is closely followed by the "use of stan- dard language and architecture framework for describing SA". Some attempt been done to improve the area of both factors above such as, modeling tool by [8], also the architecture description interchange language by [9], and the architectural model-based language by [10]. However, it not been spread out within industry so far.

The other factors that could support quantitative evaluation for SA include the formality level of SA description, documentation mechanism used during SA description, and the language used for describing SA.

We therefore believe that in order to influence the use of quantitative evaluation for SA, not only do the tools for describing SA need to be availed, but it is also important to pay close attention to the language that is used in describing SA in terms of its formality, standardization and nature. As seen from Table II, a total of 39 (out of 43) respondents identified factors that have to do with the language used in describing SA. Finally, it is also important to improve on the documentation of SA description.

Further, analysis on the main factors that discourage the use of quantitative evaluation for SA reveals that one of these factors is the "formality level of SA description" used. We think that some improvement and adjustment of Rushby's four levels of formalization [11], to suit SA will help Architects to know how far they should formalize SA.

The other main factor as identified by respondents is "the language used for describing the SA". Others include the availability of tools for describing the SA, the documentation mechanism used during SA description and the use of standard language and framework for describing SA. It is noted that two factors were identified as the major by the respondents surrounding hindrances - tools and description languages. This seems a valid expectation based on researchers preliminary investigation, showing the reliability of the results.

A closer analysis of these results with the results for the factors that could support the use of quantitative evaluation for SA shows that there is a similarity in the factors identified. As seen from Table III, the three main factors that hinder the use of quantitative evaluation in SA still revolve around the availability of tools, formality level of SA description, as well as the language used in description of SA. We therefore believe that a solution must involve 
TABLE III

IMPORTANT FACTORS THAT COULD HINDER QUANTITATIVE EVALUATION FOR ANY SA

\begin{tabular}{lccc}
\hline $\begin{array}{l}\text { What are the most important factors that could HINDER } \\
\text { quantitative evaluation for any software architecture } \\
\text { (SA)? You may choose two. }\end{array}$ & Responses & $\begin{array}{c}\text { Percentage based on who } \\
\text { responds to this question (N'=43) }\end{array}$ & $\begin{array}{c}\text { Percentage based on total } \\
\text { responses (N=50) }\end{array}$ \\
\hline The language used for describing SA & 21 & $40.5 \%$ & $34.0 \%$ \\
\hline Formality level of SA description & 5 & $50.0 \%$ & $42.0 \%$ \\
\hline $\begin{array}{l}\text { Using standard language and architecture framework for } \\
\text { describing SA }\end{array}$ & 15 & $11.9 \%$ & $10.0 \%$ \\
\hline Tools availability for describing and evaluating SA & 6 & $35.7 \%$ & $30.0 \%$ \\
\hline Documenting mechanism used during SA description & & $14.3 \%$ & $12.0 \%$ \\
\hline
\end{tabular}

TABLE IV

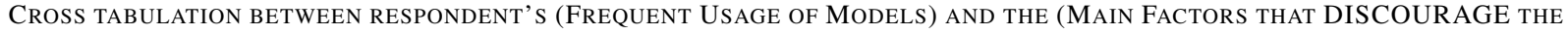
UtiLIZATION OF SA MODELLING TECHNIQUES)

\begin{tabular}{|c|c|c|c|c|c|}
\hline \multirow{2}{*}{$\begin{array}{l}\text { What are the main factors that DISCOURAGE the } \\
\text { utilization of modelling techniques to describe soft- } \\
\text { ware/system architecture? You may select up to two } \\
\text { options. }\end{array}$} & \multicolumn{5}{|c|}{$\begin{array}{l}\text { How often do you use models to describe software/system architecture during your } \\
\text { work? }\end{array}$} \\
\hline & Never & $\begin{array}{l}\text { Infrequently } \\
\quad(; 10 \%)\end{array}$ & $\begin{array}{l}\text { Reasonably frequent } \\
(i 15 \% \text { and } ; 50 \%)\end{array}$ & $\begin{array}{l}\text { Regularly }(i 50 \% \\
\quad \text { and } ; 80 \%)\end{array}$ & $\begin{array}{l}\text { Nearly } \\
\text { always } \\
(i 90 \%)\end{array}$ \\
\hline $\begin{array}{l}\text { Hard to integrate these models with other artefacts (e.g. } \\
\text { Design models), so they become standalone models, } \\
\text { which to some degree are not that useful during the } \\
\text { development of software/system }\end{array}$ & 1 & 8 & 8 & 1 & 1 \\
\hline $\begin{array}{l}\text { Lack of standardisation between existing architecture } \\
\text { modelling technique, notations, and semantics }\end{array}$ & 0 & 7 & 4 & 4 & 2 \\
\hline $\begin{array}{l}\text { Current architecture description languages (including } \\
\text { modelling languages) are still immature }\end{array}$ & 0 & 2 & 3 & 2 & 1 \\
\hline $\begin{array}{l}\text { Modelling the architecture has limited benefit to the } \\
\text { whole software/system development process, so it's to } \\
\text { some extent a waste of time and money }\end{array}$ & 5 & 3 & 3 & 0 & 1 \\
\hline $\begin{array}{l}\text { Hard to evaluate architecture models against any stake- } \\
\text { holder's quality attributes (e.g. Security, performance) }\end{array}$ & 3 & 2 & 6 & 1 & 1 \\
\hline
\end{tabular}

TABLE V

CROSS TABULATION BETWEEN RESPONDENT'S (YEARS OF EXPERIENCE) AND THE (MAIN FACTORS THAT DISCOURAGE THE UTILIZATION OF SA Modelling TechNiques)

What are the main factors that DISCOURAGE the utilization of modelling techniques to describe software/system architecture? You may select up to two options.

\begin{tabular}{|c|c|c|c|c|c|}
\hline & (years) & (years) & (years) & (years) & (years) \\
\hline $\begin{array}{l}\text { Hard to integrate these models with other artefacts (e.g. Design models), so they } \\
\text { become standalone models, which to some degree are not that useful during } \\
\text { the development of software/system }\end{array}$ & 8 & 3 & 3 & 4 & 1 \\
\hline $\begin{array}{l}\text { Lack of standardisation between existing architecture modelling technique, } \\
\text { notations, and semantics }\end{array}$ & 7 & 1 & 2 & 4 & 3 \\
\hline $\begin{array}{l}\text { Current architecture description languages (including modelling languages) are } \\
\text { still immature }\end{array}$ & 0 & 4 & 1 & 2 & 1 \\
\hline $\begin{array}{l}\text { Modelling the architecture has limited benefit to the whole software/system } \\
\text { development process, so it's to some extent a waste of time and money }\end{array}$ & 7 & 4 & 0 & 1 & 0 \\
\hline $\begin{array}{l}\text { Hard to evaluate architecture models against any stakeholder's quality attributes } \\
\text { (e.g. Security, performance) }\end{array}$ & 8 & 4 & 0 & 0 & 1 \\
\hline
\end{tabular}

How many years of experience do you have in total in the software/systems development field?

$\begin{array}{ccccc}5-10 & 10-15 & 15-20 & 20-25 & \text { Over 25 } \\ \text { (years) } & \text { (years) } & \text { (years) } & \text { (years) } & \text { (years) }\end{array}$

.


TABLE VI

CROSS TABULATION BETWEEN (MOST IMPORTANT FACTORS THAT COULD SUPPORT QUANTITATIVE EVALUATION) AND THE STATEMENT “CURRENT TECHNOLOGY ALLOWS US TO DEVELOP GENERAL SOFTWARE EVALUATION MODELS THAT ASSESS ANY SOFTWARE ARCHITECTURE AGAINST ANY QUALITY ATTRIBUTE"

\begin{tabular}{lcccccc}
\hline \multirow{2}{*}{$\begin{array}{l}\text { What are the most important factors } \\
\text { that could SUPPORT quantitative eval- } \\
\text { uation for any software architecture } \\
\text { (SA)? }\end{array}$} & $\begin{array}{l}\text { Current technology allows us to develop general software evaluation models } \\
\text { that assess any software architecture against any quality attributes. }\end{array}$ \\
\cline { 2 - 7 } & Strongly Disagree & Disagree & Neutral & Agree & Strongly Agree \\
\cline { 2 - 7 } & Count & Count & Count & Count & Count \\
\hline The language used for describing SA & 0 & 3 & 2 & 2 & 0 \\
\hline Formality level of SA description & 3 & 2 & 3 & 4 & 0 \\
\hline $\begin{array}{l}\text { Using standard language and architec- } \\
\text { ture framework for describing SA }\end{array}$ & 0 & 7 & 6 & 5 & 1 \\
\hline $\begin{array}{l}\text { Tools availability for describing and } \\
\text { evaluating SA }\end{array}$ & 2 & 5 & 10 & 2 & 1 \\
\hline $\begin{array}{l}\text { Documenting mechanism used during } \\
\text { SA description }\end{array}$ & 0 & 1 & 7 & 1 & 0 \\
\hline
\end{tabular}

these three factors.

\section{B. Two dimensional Analyses}

In order to check for any relationship between the responses to the questions under consideration in this paper, a two dimensional analysis of all combinations of questions that involve any of Q6, Q7, Q13 or Q14 was performed. This section reports the findings of these analyses for meaningful conclusions. Assumption of normality for the Likert scaled statements (Q9, Q10, Q15 to Q23) were performed using Shapiro-Wilk W statistic. Shapiro-Wilk W test confirms that each of the item was come from a normal population (p-value > .05) except Q22. So, parametric tests are applicable to all these items except Q22. The W test result for $\mathrm{Q} 22$ is $, \mathrm{W}=0.92, \mathrm{Z}=2.61, \mathrm{p}$-value $<.01$ but since Shapiro-Wilk W statistic is close to 1, parametric tests are still applicable.

In comparing all the questions that involved a nominal scale, one of the significant relationships that were noted was between "how often respondents use models" to describe software/system architecture during their work and "the main factors that encourage the utilization of modelling techniques to describe software/system architecture". A $\chi^{2}$ test conducted on this cross-relationship shows that the results are significant at $1 \%$ level $\left(\chi^{2}=56.5\right.$, $\mathrm{p}$-value $<.01)$, which shows a very strong association between the two items.

Similarly, it was noticed that a significant association (at the 5\% level) between "the main factors that discourage the utilization of modelling techniques in system/software architecture description" and "the frequency of use of software/system architecture by developers in their work" $\left(\chi^{2}=33.5\right.$, p-value $\left.<.05\right)$. The full analysis of the results is shown in Table IV.

Another significant association was noted between results of "the main factors that discourage the utilization of modelling techniques in SA description" and "the years of experience" in total in the field of software/system development $\left(\chi^{2}=30.44\right.$, p-value $\left.<.07\right)$. A cross tabulation of the results is shown in Table V.

These associations were expected since developers who never use models to describe software architecture may not be able to point to the reasons that influence them, as opposed to those who use models more often. This extends to developers who have not stayed in the development industry for long to identify the trends in the use of models in SA description.

We therefore believe that in order to improve the process of identification of these factors, it is necessary to encourage developers to use modelling techniques in SA description more frequently. More efficiency may be obtained by choosing respondents who have gained a long-time experience in system/software development for similar surveys in the future. The results also reveal less respondents with over 25 years of experience identified the factors listed as hindrances to the use of modelling in SA description. This could mean that utilization of modelling becomes easier and more efficient as the developers stay in the industry longer, or it could mean that the percentage of respondents with over 25 years experience was too low for results to be significant.

In identifying two dimensional relationships around the factors that may discourage the utilization of modelling techniques in SA description, a null hypothesis, $\mathrm{H}_{0}: \mu_{1}=\mu_{2}$ was developed alongside an alternative hypothesis, Ha: $\mu_{1}<\mu_{2}$ where, $\mu_{1}=$ the population mean of the selected item (the column variables) for the respondents who answered "YES" to the item "Hard to integrate these models with other artefacts (e.g. Design models), so they become standalone models, which to some degree are not that useful during the development of software/system" and $\mu_{2}$ $=$ the population mean of the selected item (the column variables) for the respondents who answered "NO" to the same statement above. An independent sample t-test used to test the above hypothesis with the item "Usage of software style/pattern concepts \& models during architecture devel- 
opment, increases the utilisation of modelling description languages, BUT decreases the simplicity of the architecture evaluation" showed a significance at the $5 \%$ level, $\mathrm{t}=-1.8$, p-value $<.05$, power $=.60$. To achieve 80 percent power a sample of $\mathrm{n} 1=\mathrm{n} 2=51$ needed. This shows a lower population mean for those who answered "Yes" to the hypothetical statement compared to those who answered "No".

This also shows the contribution of (software patterns) which were evaluated in the previous questionnaire in an effort to minimize the hindrances to the utilization of modelling techniques in system/software architecture description. Also, the result above could be due to the respondents' disagreement to the second part of the pattern statement, which is (Usage of software style/pattern concepts \& models during architecture development, increases the utilisation of modelling description languages, $B U T$ decreases the simplicity of the architecture evaluation).

A significant relationship was also noticed between the most important factors that could SUPPORT quantitative evaluation for any software architecture (SA) and the opinion that "Usage of software style/pattern concepts \& models during architecture development, increases the utilization of modelling description languages, BUT decreases the simplicity of the architecture evaluation", $\chi^{2}(20)=34.36$, $\mathrm{p}$-value $<.05$. This further reveals the contribution of software style/patterns on both SA evaluation as well as the use of modelling techniques in SA descriptions.

TABLE VII

PEARSON CHI-SQUARE TEST RESULTS FOR ANALYSES OF QUESTIONS Q13 AND Q22.

What are the most important factors that could $S U P$ $P O R T$ quantitative evaluation for any SA? You may choose two.

\begin{tabular}{cc}
\hline Chi-square & 30.75 \\
\hline df & 20 \\
\hline Sig. & .059 \\
\hline
\end{tabular}

Similarly, the evaluation of the statement that "there is still vagueness in the current literature concerning the differences between the architecture abstraction and high level design, which causes some confusion and perhaps wastes time during development by architects and designers" around the null hypothesis, $\mathrm{H}_{0}: \mu_{1}=\mu_{2}$ and alternative hypothesis, $H_{a}: \mu_{1} \neq \mu_{2}$ where $\mu_{1}=$ the population mean of the selected item (the column variables) for the respondents who answered "Yes" to the item "Hard to evaluate architecture models against any stakeholder's quality attributes (e.g. Security, performance)" and $\mu_{2}=$ the population mean of the selected item (the column variables) for the respondents who answered "No" to the item "Hard to evaluate architecture models against any stakeholder's quality attributes (e.g. Security, performance)" showed a significantly lower population mean for those who responded "Yes" to the item than those who responded "No", $\mathrm{t}=-1.96, \mathrm{p}$-value $=.028<.05$, power $=.46$. To achieve 80 percent power, a sample size of $\mathrm{n} 1=\mathrm{n} 2=76$ needed. The results are arrived at by considering a left-tailed population.

Also, more analysis reveals that the relationship was also detected for the factor "Most of the existing software architecture evaluation methods, produce qualitative results", $\mathrm{t}=1.94, \mathrm{p}$-value $=.03<.05$, power $=.72$. To achieve 80 percent power, a sample size of $\mathrm{n} 1=\mathrm{n} 2=34$ needed.

In a similar way, a significant relationship was established at $6 \%$ level, between the most important factors that could SUPPORT quantitative evaluation for any software architecture (SA) and the opinion about the statement "Current technology allows us to develop general software evaluation models that assess any software architecture against any quality attributes" $\chi^{2}(20)=30.75$, p-value $<.06$. The results of the cross-comparison are shown in Table VI,VII. This relationship is an indication of the effect of the use of current technology on factors that could support quantitative evaluation of SA, as well as the use of modelling in SA descriptions.

Furthermore, independent sample t-tests performed to determine the association in the agreement to the statements "Developing software/system architecture using current architectural frameworks (e.g. ISO/IEC 42010, DODAF, RUP/4+1) increases the reliability, standardization, and reusability of the resulting architecture" and "Usage of software style/pattern concepts \& models during architecture development, increases the utilization of modelling description languages, BUT decreases the simplicity of the architecture valuation" as compared with the responses to the main factors that encourage the utilization of modelling techniques to describe software/system architecture. Both statements' relationships (above) with all encouraging factors are insignificants at the level of 5\%. This independence in opinion is expected and it shows the genuineness of the responses given in this study to evaluate the factors that influence the use of modelling as well as quantitative evaluation in SA description.

In order to determine the cross-relationship between the responses with ordinal items in Q15 to 23, null and alternative hypotheses were formed equating the pairs of items. Interesting relationships were noted. For example, there was a significant relationship at the $5 \%$ level $(\mathrm{t}=2.2$, $\mathrm{p}$-value $<.05)$, power $=.74$, pointing out that the population mean of the item "Reliable tools are important for developing/or evaluating software/system architectures" is significantly higher for the respondents who replied "Yes" to the item "It makes the designers/programmers' job much easier". This is an expected relationship, showing the zeal of developers to find effective tools to make their work easier, thus supporting the use of models in SA description.

Similar relationships were noted between the population means for the item "Architecture is design, but NOT all 
design is Architecture" which is significantly higher for the respondents who replied "Yes" to the item "Makes the evaluation of stakeholders requirements for quality attributes possible in the early stages of the development lifecycle".

Generally, the responses to some of the items in the ordinal questions have identified critical factors that influence the use of models and quantitative evaluation in SA description, which required more attention from software engineers to improve the current state of the art in the domain of SA. As a result, the above improvements will impulse SA automation process in the industry.

\section{CONCLUSION AND RECOMMENDATION}

This study has helped to uncover and then confirm some of the most important factors that encourage or hinder the utilization of models in SA description as well as the use of SA quantitative evaluation. These factors include the use of SA standardized frameworks and description languages, the level of SA description formality, interface mechanism (integration) between SA artefacts and other phases within the development lifecycle (e.g requirements and design). Also, tools for describing SA are important, as well as SA documentation process.

We believe that the above factors are key to improve SA deliverables, evaluation processes, and automation procedures. It is of paramount importance to encourage the use of models in the description of system architecture due to the fact that have been identified above. Unfortunately, most of the developers don't often use models in SA descriptions, due to the reasons that have been identified. We recommend further research to focus on the solutions that could be implemented for the hindrances, while devising ways of encouraging the use of models by enhancing the encouraging factors identified above.

As identified by the two dimensional analysis, most of the experiences of developers with the use of models in their work are influenced by other factors. For example, it is clear that people have a need for tools which can make their work easier in software development. It has been clearly identified in this research that one of the most important factors that encourages the use of models in software architecture description is the ability to ease the developers' work. Thus, more emphasis needs to be given to the use of models in the developers' work. The first step to achieving this and encouraging more developers to embrace it, is to find solutions to the hindrances identified above. This is also the case for the use of quantitative evaluation of software architectures.

\section{REFERENCES}

[1] N. M. Razali and Y. B. Wah, "Power comparisons of shapiro-wilk, kolmogorov-smirnov, lilliefors and anderson-darling tests," Journal of Statistical Modeling and Analytics, vol. 2, no. 1, pp. 21-33, Retrieved 5 June 2012. 2011.

[2] D. Garlan, "Software architecture: a roadmap," in Proceedings of the Conference on The Future of Software Engineering, ser. ICSE '00. New York, NY, USA: ACM, 2000, pp. 91-101. [Online]. Available: http://doi.acm.org/10.1145/336512.336537
[3] P. Clements, Documenting Software Architectures: Views and Beyond. Boston, USA: Pearson Education, 2003.

[4] D. Milicev, Model-Driven Development with Executable UML. Indianapolis: Wiley Publishing, 2009.

[5] J. R. U. G. Graham Bleakley, Matthew Hause, "Updm - unified profile for dodaf/modaf."

[6] T. Weilkiens, Systems engineering with SysML/UML: modeling, analysis, design. Morgan Kaufmann, 2007.

[7] T. Stahl and M. Völter, Model-Driven Software Development: technology, engineering, management. Chichester, UK: John Wiley \& Sons, 2006.

[8] "http://www.atego.com/products/atego-modeler/."

[9] D. Garlan, R. Monroe, and D. Wile, "Acme: An architecture description interchange language," in Proceedings of the 1997 conference of the Centre for Advanced Studies on Collaborative research. IBM Press, 1997, p. 7.

[10] P. H. Feiler and D. P. Gluch, Model-based engineering with AADL: An introduction to the sae architecture analysis \&amp; design language. Addison-Wesley, 2012.

[11] J. M. Schumann, Automated theorem proving in software engineering. Berlin: Springer-Verlag, 2001. 